University of Nebraska - Lincoln

DigitalCommons@University of Nebraska - Lincoln

Educational Psychology Papers and

Publications

Educational Psychology, Department of

November 2000

\title{
Using the Mystery Motivator to Improve Child Bedtime Compliance
}

Kristin E. Robison

Children's Behavior Therapy Unit, Salt Lake City, UT

Susan M. Sheridan

University of Nebraska-Lincoln, ssheridan2@unl.edu

Follow this and additional works at: https://digitalcommons.unl.edu/edpsychpapers

Part of the Educational Psychology Commons

Robison, Kristin E. and Sheridan, Susan M., "Using the Mystery Motivator to Improve Child Bedtime Compliance" (2000). Educational Psychology Papers and Publications. 38.

https://digitalcommons.unl.edu/edpsychpapers/38

This Article is brought to you for free and open access by the Educational Psychology, Department of at DigitalCommons@University of Nebraska - Lincoln. It has been accepted for inclusion in Educational Psychology Papers and Publications by an authorized administrator of DigitalCommons@University of Nebraska - Lincoln. 


\title{
Using the Mystery Motivator to Improve Child Bedtime Compliance
}

\author{
Kristin E. Robinson \\ Susan M. Sheridan
}

\begin{abstract}
Child bedtime problems are commonly reported by parents. A number of behavioral techniques, including extinction of tantrum behaviors, reinforcement of compliant bedtime, and implementation of consistent bedtime routines have been successful in improving bedtime compliance. The present study examined the effects of the "Mystery Motivator" (MM), a behavioral contract designed to remediate bedtime problems by delivering random reinforcement. Emphasis was placed on the optimal use of clinical intervention by enlisting parents as primary change agents in the home setting. Three adults and their four children, aged 3-5 years, participated. Three of the four children showed substantial changes in both time out of bed and bedtime noncompliance between baseline and treatment phases. A fourth child showed less improvement. Parent participants demonstrated understanding of the materials and successfully implemented the home program. Both parent and child participants rated the Mystery Motivator reinforcement system as an acceptable intervention. [Article copies available for a fee from The Haworth Document Delivery Service: 1-800-342-9678. E-mail address: getinfo@haworthpressinc.com <Website: http://www.haworthpressinc.com>]
\end{abstract}

KEYWORDS. Bedtime, behavioral, child, compliance, mystery motivator

Kristin E. Robinson is affiliated with Children's Behavior Therapy Unit, Salt Lake City, UT.

Susan M. Sheridan is affiliated with Educational Psychology Department, University of Nebraska, Lincoln, NE.

Address correspondence to Kristin E. Robinson, Children's Behavior Therapy Unit, 668 South 1300 East, Salt Lake City, UT 84102 (Email: krisr@vhm.com).

Child \& Family Behavior Therapy, Vol. 22(1) 2000

(C) 2000 by The Haworth Press, Inc. All rights reserved. 
Getting children to bed and asleep presents a widespread problem for parents. Refusal to go to bed and frequent night waking, have been reported in $15 \%$ to $30 \%$ of large normative samples (Blader, Koplewicz, Abikoff, \& Foley, 1997; Lozoff, Wolf, \& Davis 1985; Richman, 1981). An ongoing struggle to settle a child at bedtime can have negative effects on the entire family system (Stores, 1996) and has been linked to parenting stress (Wolfson, Lacks, \& Futterman, 1992) and marital discord (Stores, 1996).

Popular literature abounds with references to this issue (e.g. Blum, 1994; Cassidy, 1996). For example, a recent Good Housekeeping article offers advice on "Helping your child-and you-get a good night's sleep" (Siegel, 1995). Contemporary parenting books include chapters that address the issue of bedtime problems (Forehand \& Long, 1996; Szykula, 1991), and at least one entire volume has been written on the topic (Ferber, 1985).

Typical parent responses to bedtime noncompliance include "giving in" to the child's tantrum, remaining with the child until asleep, feeding the child, or otherwise repeatedly attending to the child (Minde, Faucon, \& Falkner, 1994; Seymour, Bayfield, Brock, \& During, 1989; Stores, 1996). Richman (1981) reported that 35\% of the resistant children in her sample slept in the parents' room on 3 or more nights per week. These types of unplanned "interventions" only serve to strengthen the child's resistance to bedtime limits. Having a parent sleep with a child in response to opposition to bedtime reinforces the child's delay in going to sleep (Blader et al., 1997). Parental attending behaviors both reinforce child resistance, and can have detrimental effects on marital relations and the family system (Jones \& Verduyn, 1983: Walters, 1993). Given that bedtime problems are common, persistent, and potentially disruptive, an examination of effective and acceptable treatment methods is warranted.

A number of studies suggest that the most promising intervention for bedtime noncompliance is a combination of education and behavioral management, employing the parents as primary change agents (Adair, Zuckerman, Bauchner, Philipp, \& Levenson, 1992; Edwards \& Christophersen, 1994; Scott \& Richards, 1990; Wolfson et al., 1992). Commonly used behavioral interventions for bedtime problems include consistent bedtime routines (Ashbaugh \& Peck, 1998; Minde et al., 1994; Piazza \& Fisher, 1991), extinction (Chadez \& Nurius, 1987), and graduated extinction (Durand \& Mindell, 1990; Rolider \& Van 
Houten, 1984a). Praise and reinforcement, used to a lesser extent (Milan, Mitchell, Berger, \& Pierson, 1982; Richman, Douglas, Hunt, Lansdown, \& Levere, 1985; Rolider \& Van Houten, 1984b), warrant further investigation. The most commonly applied behavioral strategies have been the combination of consistent bedtime routines and extinction procedures (Adams \& Rickert, 1989; Allison, Burke, \& Summers, 1993; Jones \& Verduyn, 1983; Minde et al., 1994) (Table 1).

The use of behavioral contracting appears to be absent from the literature regarding bedtime problems. A behavior contract, also known as a contingency contract, is a formal agreement that a reward will follow a specified behavior (Rhode, Jenson, \& Reavis, 1992). Contracting, widely researched in the past two decades, appears to have gained empirical support (Carns \& Carns, 1995; Kirschenbaum, Dielman, \& Karoloy, 1982). Contracting has been widely applied to manage child behavior, including tantrums, school refusal, and toileting problems (Dardig \& Heward, 1981).

A key component of any behavior contract is adequate reinforcement. An interesting and individualized variety of rewards are chosen carefully to provide motivation for children (Rhode et al., 1992). A recent development in behavioral contracting is the Mystery Motivator (Jenson, Rhode, \& Reavis, 1994). This combines the classical components of contracting (i.e., formalized conditions, clear goals) with a novel approach in enhancing child motivation.

\section{The "Mystery Motivator"}

The Mystery Motivator (MM) is a behavior contract designed to deliver random reinforcement for appropriate behavior (Jenson et al., 1994). The MM consists of an objectively-defined goal (e.g., be in bed with the lights out by 8 PM each night without getting up more than once until morning), which is reinforced at a specified time each day by having the child color in a square with a "developer" pen. A reward is issued if the developer pen changes color within the square. The MM combines several behavioral components into a comprehensive reinforcement delivery system. The MM provides objectively-defined behavioral goals, clearly defined performance criteria, a simple form for recording data (which can be publicly posted to serve as a prompt for behavior elicited), and a variable rate of reinforcement to the child for appropriate behavior. A variable schedule of reinforcement heightens the child's anticipation for the reward, and decreases 
TABLE 1. Use of Behavioral Strategies in Remediating Child Bedtime Problems

\begin{tabular}{|c|c|c|c|}
\hline Author (year) & Subjects & Method & Outcome \\
\hline Ashbaugh, \& Peck (1998) & $\begin{array}{l}\text { One nondisabled } 2 \text { year-old } \\
\text { girl. }\end{array}$ & $\begin{array}{l}\text { Replicated Pita \& Fisher } \\
(1991) \text { study using faded } \\
\text { bedtime and response cost }\end{array}$ & $\begin{array}{l}\text { Treatment package was } \\
\text { effective in improving sleep } \\
\text { wake cycle of the participant. }\end{array}$ \\
\hline $\begin{array}{l}\text { Minde, Faucon, \& Falknet } \\
\text { (1994) }\end{array}$ & $\begin{array}{l}28 \text { children (12-36 mos.) and } \\
30 \text { matched controls }\end{array}$ & $\begin{array}{l}\text { Specific bedtime routines, } \\
\text { Graduated extinction }\end{array}$ & $\begin{array}{l}21 \text { families judged themselves } \\
\text { to have achieved substantial } \\
\text { improvement m their child's } \\
\text { sleep habils. Maintenance } \\
\text { shown at } 4 \text {-month follow-up }\end{array}$ \\
\hline $\begin{array}{l}\text { Allison, Burke, \& Summers } \\
\text { (1993) }\end{array}$ & $\begin{array}{l}\text { One } 8 \text { year-old child with } \\
\text { Down's syndrome }\end{array}$ & $\begin{array}{l}\text { Structured bedtime routine and } \\
\text { routine plus faded extinction }\end{array}$ & $\begin{array}{l}\text { During baseline, the child spent } \\
\text { only } 6 \% \text { of the night sleeping } \\
\text { alone. This rate was increased } \\
\text { to } 26 \% \text { with the use of a } \\
\text { routine, and to } 78 \% \text { with the } \\
\text { addition of extinction after a } \\
\text { treatment period of } 70 \text { days. } \\
\text { These improvements were } \\
\text { maintained at } 6 \text {-week and 6- } \\
\text { month follow-up. }\end{array}$ \\
\hline Piazza \& Fisher (1991) & $\begin{array}{l}4 \text { individuals with } \\
\text { developmental delays } \\
\text { (age 3-19) }\end{array}$ & $\begin{array}{l}\text { Faded bedtime routine and } \\
\text { response cost }\end{array}$ & $\begin{array}{l}\text { All } 4 \text { participants showed } \\
\text { increased sleep through the } \\
\text { night. Three of the four } \\
\text { showed decreased sleep during } \\
\text { the day. }\end{array}$ \\
\hline Durand \& Mindell (1990) & One 14 month-old child & $\begin{array}{l}\text { Graduated extinction of } \\
\text { parental attention to child } \\
\text { tantrums }\end{array}$ & $\begin{array}{l}\text { Extinction produced rapid } \\
\text { reduction in tantrums. } \\
\text { Additionally, data on parental } \\
\text { depression and marital } \\
\text { satisfaction showed general } \\
\text { improvement. }\end{array}$ \\
\hline Adams \& Kickert (1989) & $\begin{array}{l}38 \text { children ( } 1.5-4 \text { years-old), } \\
\text { recruited via newspaper ad }\end{array}$ & $\begin{array}{l}\text { Compared consistent positive } \\
\text { bedtime routine with extinction } \\
\text { and control groups }\end{array}$ & $\begin{array}{l}\text { Children in the two treatment } \\
\text { groups had tantrums less } \\
\text { frequently and for shorter } \\
\text { periods than those in the } \\
\text { control group. Parents in the } \\
\text { positive routine group reported } \\
\text { improved marital satisfaction } \\
\text { also. }\end{array}$ \\
\hline $\begin{array}{l}\text { Seymour, Brock, During, \& } \\
\text { Poole (1989) }\end{array}$ & $\begin{array}{l}45 \text { children (9 months to } 5 \\
\text { years-old) in New Zealand }\end{array}$ & $\begin{array}{l}\text { Compared three groups: } \\
\text { bedtime routine, written } \\
\text { information only, and a control } \\
\text { group. }\end{array}$ & $\begin{array}{l}\text { Results support the use of } \\
\text { written parent instructions with } \\
\text { or without therapist support. } \\
\text { Both treatment groups showed } \\
\text { similar improvements over the } \\
\text { control group. }\end{array}$ \\
\hline Chadez \& Nurius (1987) & One 7-month-old infant & Extinction & $\begin{array}{l}\text { Full remission of crying within } \\
3 \text { weeks of extinction. A } \\
\text { natural reversal period } \\
\text { (vacation) showed an increase } \\
\text { in crying, and use of extinction } \\
\text { was again successful within } \\
\text { three days. }\end{array}$ \\
\hline $\begin{array}{l}\text { Richman, Douglas, Hunt, } \\
\text { Lansdown, \& Levere (1985) }\end{array}$ & 35 children aged $1-5$ years-old & $\begin{array}{l}\text { Extinction of parental attention } \\
\text { to tantrums, verbal praise, and } \\
\text { tangible reinforcement to } \\
\text { children for being in bed on } \\
\text { time }\end{array}$ & $\begin{array}{l}\text { Improvement occurred in } 77 \% \\
\text { of the child participants }\end{array}$ \\
\hline Sanders \& Christensen (1985) & $\begin{array}{l}20 \text { children aged } 2.5 \text { to } 7 \\
\text { years-old }\end{array}$ & $\begin{array}{l}\text { Compared the effects of child } \\
\text { management strategies alone, } \\
\text { with child management plus } \\
\text { planned activities with parents }\end{array}$ & $\begin{array}{l}\text { Both conditions showed similar } \\
\text { improvements in child } \\
\text { oppositional behavior at } \\
\text { bedtime. Improvements were } \\
\text { maintained at 3-month follow-up. }\end{array}$ \\
\hline
\end{tabular}


TABLE 1 (continued)

\begin{tabular}{|c|c|c|c|}
\hline Author (year) & Subjects & Method & Outcome \\
\hline Rolider \& Van Houten (1984a) & $\begin{array}{l}\text { Three children }(2-2.5 \text { years } \\
\text { old) }\end{array}$ & $\begin{array}{l}\text { Gaduated extinction of child } \\
\text { crying }\end{array}$ & $\begin{array}{l}\text { All children showed } \\
\text { improvement once the } \\
\text { extinction time exceeded the } \\
\text { tantrum consistently }\end{array}$ \\
\hline Rolider \& Van Houten (1984b) & One 4.5 year-old child & $\begin{array}{l}\text { Compared the effects of DRO, } \\
\text { DRO plus extinction, and DRO } \\
\text { plus reprimands }\end{array}$ & $\begin{array}{l}\text { All conditions resulted in } \\
\text { improvements. DRO plus } \\
\text { reprimands demonstrated the } \\
\text { most improvement overall }\end{array}$ \\
\hline Jones \& Verduyn (1983) & $\begin{array}{l}19(1-5 \text { years-old) children } \\
\text { referred to a general } \\
\text { practitioner for sleep problems }\end{array}$ & $\begin{array}{l}\text { Implementation of a consistent } \\
\text { bedtime routine, extinction of } \\
\text { parental attention to tantrums }\end{array}$ & $\begin{array}{l}53 \% \text { of the children's sleep } \\
\text { problems were resolved. } 37 \% \\
\text { showed partial resolution. All } \\
\text { improvement was maintained } \\
\text { at 6-month folliow-up }\end{array}$ \\
\hline $\begin{array}{l}\text { Milan, Mitchell, Berger, \& } \\
\text { Pierson (1982) }\end{array}$ & $\begin{array}{l}\text { Three emotionally disturbed, } \\
\text { severely handicapped children } \\
\text { (ages 2-15) }\end{array}$ & $\begin{array}{l}\text { Verbal praise and a fixed } \\
\text { bedtime routine }\end{array}$ & $\begin{array}{l}\text { All subjects displayed } \\
\text { significant improvement within } \\
\text { a 2-week period. No bedtime } \\
\text { problems were noted at } 1 \text {-year } \\
\text { follow-up }\end{array}$ \\
\hline $\begin{array}{l}\text { Rapoff, Christophersen, \& } \\
\text { Rapoff (1982) }\end{array}$ & $\begin{array}{l}\text { Six children (ages } 2-4.5 \text { years- } \\
\text { old) referred to a heatth clinic } \\
\text { for bedtime problems }\end{array}$ & $\begin{array}{l}\text { Written handout to parents } \\
\text { describing procedures (bedtime } \\
\text { routine and extinction) for } \\
\text { managing bedtime problems. }\end{array}$ & $\begin{array}{l}\text { Results showed a decrease in } \\
\text { the rate of crying for } 3 \text { of the } 6 \\
\text { children following treatment. } \\
\text { Parental inconsistency with } \\
\text { extinction was noted as a } \\
\text { possible confounding factor }\end{array}$ \\
\hline
\end{tabular}

the likelihood of a post-reinforcement pause (Cooper, Heron, \& Heward, 1987; Rhode et al., 1992).

Moore, Waguespack, Wickstrom, Witt, and Gaydos (1994) found the $\mathrm{MM}$ to be successful in increasing compliance in a classroom setting. In this study, the MM was applied across 9 students (all male; five 3rd graders and four 5th graders) from two classrooms. Eight of the students showed substantial improvement in homework compliance following intervention. Data gathered from teachers and students also suggested that the MM is an acceptable intervention that can be implemented with a high degree of treatment integrity. Although the MM has not been investigated as an intervention with parents in a home setting, these preliminary findings suggest that the MM could be applied as a tool in teaching parents how to reinforce child compliance.

The Mystery Motivator capitalizes on two basic behavioral principles: operationalization and reinforcement. First, a target behavior is operationalized. The MM uses a behavior contract format to define the behavioral goal (e.g., going to bed at bedtime). Second, the MM utilizes an intermittent schedule of reinforcement to promote behavioral motivation (Malott, Whaley, \& Malott, 1991).

Previous research supports the use of behavioral techniques (such as consistent routines and extinction) with and without the addition of written materials for decreasing bedtime noncompliance among chil- 
dren. The use of parents as primary change agents is also well-supported. Behavioral strategies of reinforcement and contracting, less rigorously examined, warrant more attention.

The MM is an innovative technique that combines contracting with variable reinforcement. The $\mathrm{MM}$ has been successfully applied to classroom problems but has yet to be studied as a therapeutic tool in a home setting. No known study has examined the MM intervention, administered by parents, to increase child compliance in any setting. Therefore the purpose of this study was to investigate the efficiency of a standardized use of the MM with nonreferred children with bedtime compliance problems.

\section{METHOD}

\section{Participants}

Four children (ranging in age from 5 to 8 years), and their parents served as participants recruited through local daycare facilities through an advertisement in a parenting newspaper. Upon screening for the study, all children were reported to meet study selection criteria of having spent at least 30 minutes out of bed each night after bedtime for a majority of the days within the prior two weeks. All children demonstrated disruptive behavior at bedtime, including crying, arguing, yelling, and physical aggression (e.g., throwing objects, hitting), according to parent report. Parent reports of these behaviors were supported by 30-minute observations conducted in the home by trained observers during the baseline phase. None of the participants had psychiatric diagnoses or received special education services at the time of the study. A brief description of each participant follows (all names are fictitious).

R.J. was a 5 year-old boy living with his biological parents and two year-old sister. R.J.'s parents had no bedtime routine, and asked the boy to go to bed at different times each night, depending upon their schedule. When asked to go to bed, R.J.'s typical behavior included ignoring the request and whining. Once in bed, R.J. got up several times during the night to play in his room or request parental attention. His parents responded inconsistently, sometimes paying attention to him, and at other times yelling at him or spanking him.

Victoria, a 5 year-old girl, lived with her divorced mother, 8 year- 
old brother, and 13 year-old sister. Victoria's family had a history of domestic violence and her siblings were involved in mental health treatment, though she was not. Noncompliance manifested as whining, crying, and yelling, lasted an estimated average of 30 minutes per night. Victoria's mother was aware of her tendency to "give in" to this behavior and reported feeling overwhelmed by the more serious behavior problems of the other children.

Tony and Zeke, biological brothers aged 8 and 5, respectively lived with their biological parents, a four year-old sister, and a 16 year-old sister. The boys did not have a specific bedtime, and their mother acknowledged her difficulty in setting limits for her children.

\section{Dependent Variables}

Shapiro (1987) described several factors that must be considered when evaluating intervention outcomes, including efficacy, acceptability, and integrity of treatments. Dependent variables were chosen to capture outcomes based on these guidelines.

\section{Bedtime Noncompliance}

For present purposes noncompliance was defined as the child being out of bed for any reason after the expected bedtime, and/or in bed making noise that could be heard from outside the bedroom. Bedtime noncompliance was measured in two ways: (a) time spent out of bed after bedtime (duration), and (b) percentage of observational intervals that a child was out of bed or noisy in bed during a 30 minute direct observation period (rate). Duration recording was used to measure the number of minutes a child spent out of bed after bedtime. Specifically, both parents and observers started the stopwatch at the assigned bedtime if the child was out of bed, then stopped the watch once the child was in bed and quiet (no sound heard outside bedroom). If the child got up for any reason, the stopwatch was again started until he or she was in bed and quiet.

Rate of noncompliance (i.e., out of bed and/or not quiet) was assessed using 30-second partial interval recording. Direct observers entered homes immediately prior to the child's target bedtime and collected data using a behavioral observation coding system (Forehand \& McMahon, 1981). Noncompliance was recorded if the child was not in bed and quiet at any time during the 30 -second interval. 
Observers used beep-tapes to signal the observer to record intervals. Direct observations of noncompliance were conducted an average of 3 days per experimental phase for 30 minutes per observation session.

Reliability. Reliability checks employed a second observer to ensure that data were recorded accurately. Inter-rater reliability checks were performed in $25 \%$ of the total number of observations selected randomly across all phases. During reliability checks, a second observer sat next to the first, sharing headphones connected to a 30 -second beep tape. When the observers heard the tone sound they recorded any noncompliance and moved to the next interval. Interrater reliability was calculated using both percent agreement and the Kappa statistic.

\section{Parent Acquired Knowledge}

A 10 -item, multiple-choice quiz was given to the parents to determine if they had read and understood the intervention procedures, including general concepts of reinforcement. This quiz was administered during the baseline phase of the study, and again after the intervention was implemented.

\section{Acceptability}

The Behavioral Intervention Rating Scale (BIRS; Elliott \& Von Brock Treuting, 1991) was used to measure treatment acceptability among parent participants. The BIRS is a 24-item measure, comprised of a 6-point rating scale (i.e., strongly disagree to strongly agree) of statements regarding acceptability of the intervention. Statements relate to such characteristics as treatment efficacy, problem severity, and negative side-effects. Factor analysis of the BIRS yielded 3 factors: (a) treatment acceptability, (b) treatment effectiveness, and (c) time of effect (Elliott \& Von Brock Treuting, 1991). The BIRS has been shown to provide valid measures of overall treatment acceptability (Elliott \& Von Brock Treuting, 1991).

Child acceptability of the intervention was measured using the Child Intervention Rating Profile (CIRP; Witt \& Elliott, 1985). This study modified the CIRP by replacing the general wording (e.g., "method") with the specific term "Mystery Motivator." The 7-item scale, read to younger children by parents, assessed the child's perception of acceptability on a 6-point Likert scale of agreement (i.e., "I 
agree" to "I do not agree"). The CIRP was administered to child participants during the last week of the intervention condition.

\section{Integrity}

Observers completed a treatment integrity form pertaining to parent behaviors at each observation period. The purpose of this form was to assess parent adherence to the intervention (e.g., using a stopwatch to measure accurately the time the child actually spent out of bed as opposed to guessing). Once parents started intervention implementation they completed a brief daily form indicating the components of the training program that were applied. This form measures how closely the parent followed the prescribed directions of the Mystery Motivator. For example, the form asks if the parent allowed the child to fill in an earned square the next morning. Item responses are "yes," "no," or "not applicable." A treatment integrity score is obtained by dividing the number of "yes" scores by the number of possible "yes" items (N/A items are not counted). A score of $100 \%$ is the highest level of treatment integrity possible.

\section{Data Collection and Reliability}

All instruction and intervention procedures occurred in the participants' homes. Data were collected by parents and independent observers. Parents recorded duration out of bed with a stopwatch to record the total number of minutes out of bed prior to and during the child's bedtime. Trained observers used Forehand and McMahon's (1981) Behavioral Coding System to record noncompliant behavior at bedtime during a 30-minute period before bedtime. Noncompliant behavior was defined as the child being out of bed or in bed making noise audible from outside the bedroom. Observers also used stopwatches to record time out of bed.

\section{Procedures}

A multiple baseline across participant design (Baer, Wolf, \& Risley, 1968) was utilized. All child participants experienced baseline and intervention phases. Follow-up data were obtained for two participants. 
Baseline. During the baseline phase, parents recorded the number of minutes the child was not in bed and quiet. None of the parents had consistent bedtimes for their children, so parents were asked to identify a bedtime goal in order to schedule observations. Observers recorded duration of times out of bed over 30 -minute observation periods before and during child bedtimes. The baseline phase lasted 6 days for R.J., 9 days for Victoria, and 15 days for Tony and Zeke. The knowledge acquisition inventory was administered to parents during the baseline phase.

Intervention. The experimental condition consisted of brief parent instruction with supplemental instructional materials. The investigator met with parents in their homes prior to the intervention phase to explain the procedures of the Mystery Motivator. This meeting lasted approximately one hour. During this time, the investigator summarized the intervention plan and gave all parents a treatment manual that detailed the treatment package. The manual also described possible scenarios that may hinder success of the treatment package and suggested remedies. For example, the manual suggested that parents not attend to out of bed behavior of children, instead clearly telling their children to return to bed. The treatment manual outlined the following components: (a) definition of the Mystery Motivator; (b) steps for implementing the Mystery Motivator; and (c) common problems and solutions for implementation. The 10-page manual focused on bedtime compliance as an example of using the Mystery Motivator. A more detailed description of implementing the Mystery Motivator may be found in Jenson, Rhode and Reavis (1994).

During parent instruction, parents were given all supplies, including age-appropriate rewards (e.g., small toys and edible items), all program forms, and one color change marker. Parents were given time to ask questions about the materials, and encouraged to contact the investigator with any further questions. None of the parents contacted the investigator, or asked the observers for assistance. The knowledge acquisition inventory was administered to parents in the week following instruction.

The investigator contacted each parent within the first three days of the intervention phase to assess understanding and offer technical assistance. All parents demonstrated an understanding of the Mystery Motivator procedures.

The Mystery Motivator program allowed children to earn small 
rewards for appropriate bedtime behavior. Each morning, the child chose one item from a grab-bag if he or she had less than 10 minutes out of bed recorded during the night before. All contracts were premarked, and had a "hit" rate of four squares (of seven) in the first week of intervention, and faded in the second week to three squares per week for subsequent weeks. The treatment package began with a higher rate of reinforcement (.57) to maximize the potential for children to be rewarded for good bedtime behavior. A lower rate (.43) was used in subsequent weeks to promote maintenance of behavior. The intervention phase lasted 27 days for R.J., 24 days for Victoria, and 18 days for Tony and Zeke. Data collection ceased following the 33rd day of the study and no direction was given to parents either to continue or discontinue the Mystery Motivator procedures.

Follow-up. Six weeks after the last intervention phase (day 33 of the study), observers returned to participants' homes to collect followup data. At this time, parents resumed data collection as before. The follow-up phase lasted one week. Tony and Zeke's mother declined to participate in the follow-up phase, citing summer hours as a reason to abandon a consistent bedtime routine. Therefore, follow-up data were collected only for R.J. and Victoria.

\section{RESULTS}

Visual inspection of data reveals a moderate degree of variability during baseline periods in both duration out of bed and observed bedtime noncompliance. Three of the four participants (R.J., Tony, and Zeke) demonstrated stabilization of data in the intervention phase, while the fourth participant (Victoria) continued to show variable performance.

Magnitude of change, represented by a change in mean level across phases, is evident in three participants (R.J., Tony, and Zeke), both in duration out of bed and observed bedtime noncompliance. Magnitude of change is further demonstrated by examining the percentage of non-overlapping data points across phases. Data for three of the four participants (R.J., Tony, and Zeke) clearly suggested change in the direction of improvement (100\% non-overlapping data). Analysis of data for a fourth participant (Victoria) was less conclusive (75\% non-overlapping data). Specific findings are discussed below. 


\section{Duration}

Figure 1 depicts individual participant data for duration of out of bed behavior after bedtime collected by parents. It was anticipated that all participants would demonstrate high baseline levels of time spent out of bed after bedtime due to selection criteria (average 30 minutes out of bed for the majority of days in the previous two weeks).

During the baseline (A) phase, all participants averaged more than 30 minutes out of bed after bedtime, indicating that going to and remaining in bed was a problem. Three out of four participants (R.J., Tony, Zeke) showed substantial decreases in minutes out of bed after the intervention was implemented. These participants averaged 360 total minutes out of bed during baseline, and 26 minutes out of bed at intervention, with $98 \%$ non-overlapping data. Participants not exposed to the intervention showed continuous high levels of duration out of bed during the staggered baseline phases, while participants in the treatment phase demonstrated reduced time out of bed. During followup, one participant (R.J.) maintained low time out of bed and another (Victoria) demonstrated increased time out of bed.

\section{Observed Noncompliant Behavior}

Noncompliant behavior was measured by observers using a structured procedure in participants' homes during bedtime. It should be noted that observer data are based on 30-minute periods of observation. Figure 2 presents percentages of observed noncompliance for all participants. It was anticipated that all participants would demonstrate high baseline levels of noncompliance at bedtime. Home observations supported this assumption, with three of four participants (R.J., Tony, Zeke) averaging above $95 \%$ noncompliance during bedtime. Observed noncompliance decreased across all participants during the intervention phase, with all participants averaging less than $18 \%$ noncompliance. Baseline percentages remained high for those participants not exposed to the intervention whereas participants entering the treatment condition showed treatment effects in the appropriate direction.

During the follow-up period, R.J. averaged $69 \%$ observed noncompliance across three observation nights. Victoria averaged $29 \%$ observed noncompliance, over three observation nights. No observational data are available for Tony and Zeke during the follow-up period. 
FIGURE 1. Total Number of Minutes Out of Bed per Evening

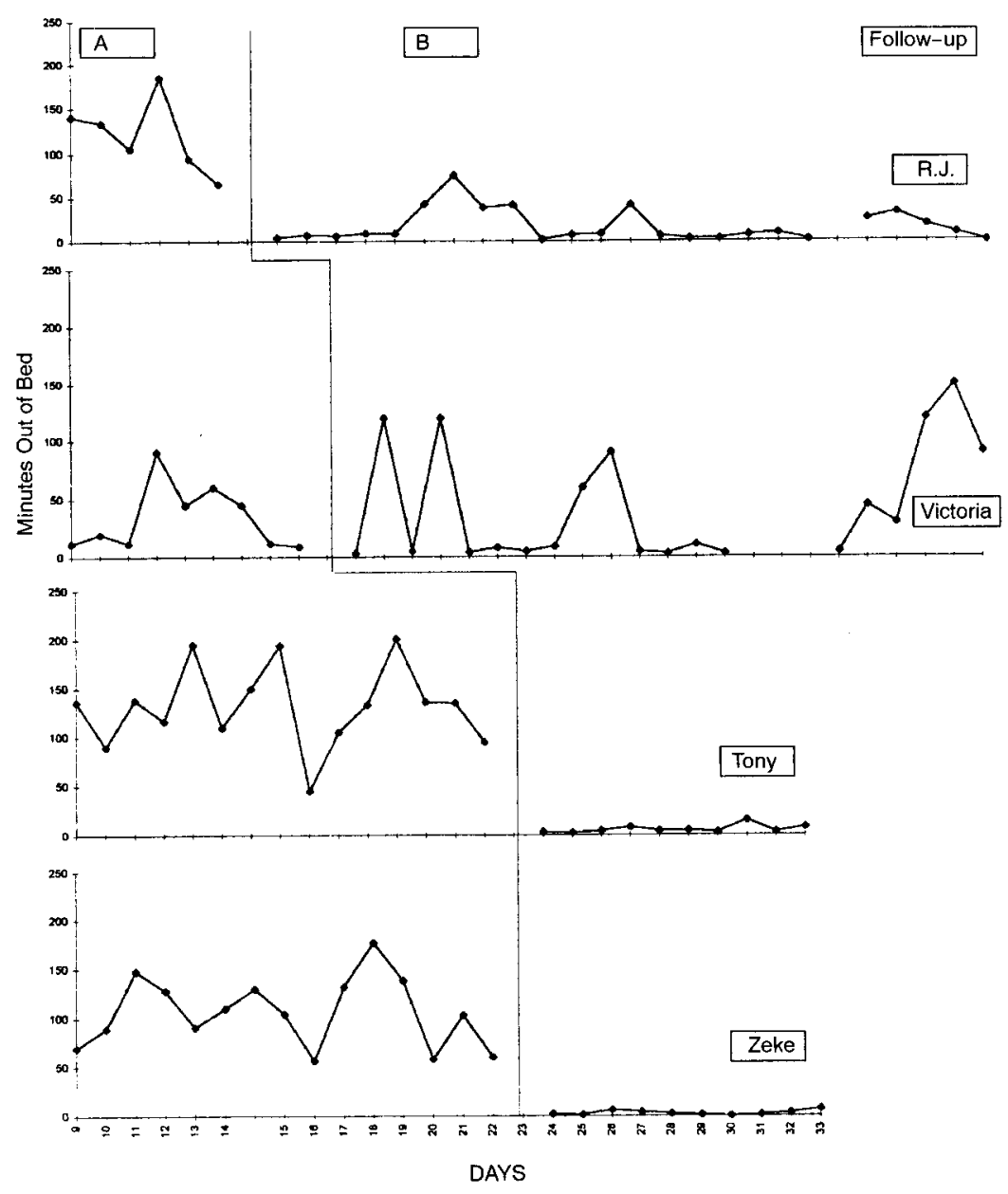

Reliability. Interrater reliability was established between observers by using two observers in participants' homes for $25 \%$ of the total observations. Interrater reliability of observed child noncompliance at bedtime was $96 \%$ overall. This was calculated as a percentage of interval by interval comparisons in which the observer and the second observer agreed on the occurrence of child noncompliance divided by 
the total number of observed intervals. Reliability was further established by calculating Cohen's Kappa statistic (Cohen, 1960). The kappa coefficient determines the agreement between rates corrected for chance (Gelfand \& Hartmann, 1984). In this study, the kappa was .97, suggesting a high interrater reliability while ruling out chance agreements.

Interrater reliability between parents' and observers' duration data was $90 \%$. This percentage was derived by dividing the total agreements (within 3 minutes) by the total number of observations. A Pearson correlation of these data yielded .97 agreement. These estimates suggest that parents accurately recorded children's bedtime behavior (Tables 2 and 3).

\section{Parent Acquired Knowledge}

All parents demonstrated satisfactory acquisition of knowledge related to the Mystery Motivator program. The average score for all parent participants rose from $73 \%$ at pre-test, to $90 \%$ following parent training. It is notable that two parents demonstrated adequate knowledge (above $75 \%$ ) prior to the intervention being implemented.

TABLE 2. Average of Time Out of Bed per Evening and Percentage of Nonoverlapping Data

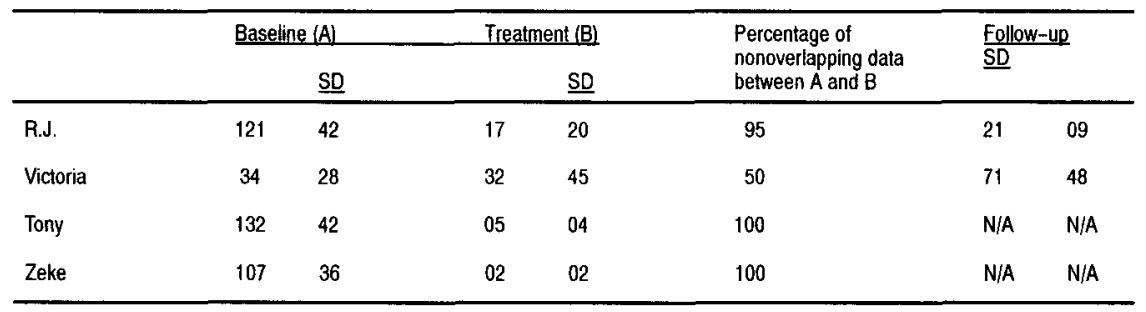

TABLE 3. Percentage of Observed Noncompliance and Nonoverlapping Data

\begin{tabular}{|c|c|c|c|c|c|c|c|}
\hline \multirow[b]{2}{*}{$\begin{array}{l}\text { R.1. } \\
\text { Victoria } \\
\text { Tony } \\
\text { Zeke }\end{array}$} & \multicolumn{2}{|c|}{ Baseline (A) } & \multicolumn{2}{|c|}{ Treatment (B) } & $\begin{array}{l}\text { Percentage of } \\
\text { nonoverlapping data } \\
\text { between A and B } \\
\begin{array}{c}100 \\
75\end{array}\end{array}$ & \multicolumn{2}{|c|}{$\begin{array}{l}\text { Follow-up } \\
\mathrm{SD}\end{array}$} \\
\hline & $\begin{array}{r}100 \\
37 \\
97 \\
97\end{array}$ & $\begin{array}{l}00 \\
12 \\
07 \\
07\end{array}$ & $\begin{array}{l}15 \\
17 \\
08 \\
07\end{array}$ & $\begin{array}{l}09 \\
15 \\
06 \\
01\end{array}$ & $\begin{array}{r}100 \\
75 \\
100 \\
100\end{array}$ & $\begin{array}{l}69 \\
29 \\
\text { N/A } \\
\text { N/A }\end{array}$ & $\begin{array}{l}19 \\
20 \\
\text { N/A } \\
\text { N/A }\end{array}$ \\
\hline
\end{tabular}


FIGURE 2. Percentage of Bedtime Noncompliance

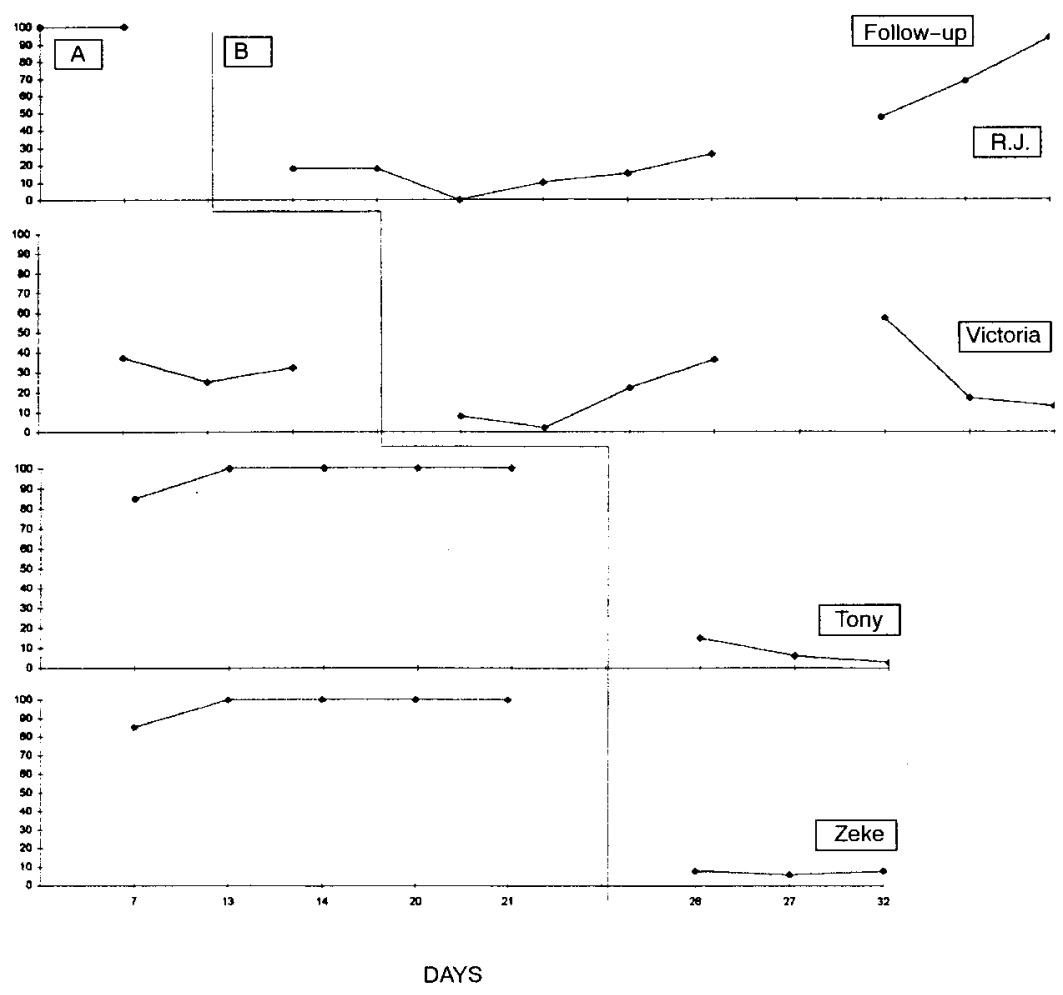

\section{Treatment Integrity}

Observer-collected data suggest that the Mystery Motivator package was implemented as described. Parent-completed checklists indicated that treatment components, such as giving a clear bedtime direction and monitoring time out of bed, were adhered to as prescribed. All parents combined averaged $99 \%$ on self-monitored treatment integrity checklists. These data are supported by $100 \%$ reliability across independent observers.

\section{Treatment Acceptability}

All parents rated the Mystery Motivator method positively on the Behavioral Intervention Rating Scale (Elliott \& Von Brock Treuting, 
1991), with an average item score across all parent participants of 5.3 (possible range $=1-6$ ). Similarly, all children rated the Mystery Motivator positively on the Child Intervention Rating Profile (Witt \& Elliott, 1985), suggesting that the children felt that the package was fair and effective and that it elicited few negative side-effects. The average item score across all child participants was 5.54 (possible range $=1-6$ ).

\section{DISCUSSION}

This study demonstrates that the Mystery Motivator is an effective and acceptable treatment for bedtime noncompliance. Issues of treatment efficacy, integrity, and acceptability are discussed below. Research limitations and possible future implementations are also explored.

\section{Treatment Effectiveness}

Of the four child participants, three (R.J., Tony, Zeke) displayed overall decreases in bedtime noncompliance during treatment conditions, possibly due to the Mystery Motivator package. The fourth child (Victoria) displayed improvements to a lesser degree. Time out of bed after bedtime showed a marked improvement in the treatment condition across participants.

All participants' performance was variable within the baseline phase, and ranges were large. It is likely that this is related to inconsistent directions from parents as well as lack of bedtime routines. Data became more stable within the treatment condition for the three participants evidencing the most progress. The fourth participant, Victoria, showed variable data across all phases, possibly due to her chaotic family situation (i.e., an out-of-home placement due to allegations against a parent).

Treatment efficacy demonstrated in this study supports previous findings that consistent bedtime routines (Allison et al., 1993; Minde et al., 1994; Piazza \& Fisher, 1991) and reinforcement (Milan et al., 1982; Rolider \& Van Houten, 1984b) are effective in improving child bedtime compliance. The Mystery Motivator capitalizes on the success of these strategies by adding a behavioral contract format. The Mystery Motivator further provides a variable rate of reinforcement, thereby reducing the likelihood of post-reinforcement pause. 
This study notes several key factors described in previous research that maintain child bedtime noncompliance, including lack of a consistent bedtime routine, parental attention to tantrums and failure to reinforce compliance (Blader et al., 1997; Minde et al., 1994; Stores, 1996; Walters, 1993). The Mystery Motivator addresses these factors by providing a clear bedtime goal and reinforcing child compliance. High acceptability ratings on the BIRS and CIRP compare closely with the high parent and child acceptability ratings obtained by Moore et al. (1994) in a classroom-based study using the Mystery Motivator.

\section{Limitations}

A primary goal of research is to discover functional relationships between independent and dependent variables, while at the same time minimizing the likelihood that behavior changes are the results of unknown or uncontrolled variables (Cooper, Heron, \& Heward, 1987). Although this study has introduced important information regarding the use of the Mystery Motivator to reduce child bedtime problems, the study has several limitations. Limitations discussed below include issues of internal and external validity. Comments regarding the unexpected results for Victoria are also provided.

Improvements among participants were likely due to the comprehensive nature of the treatment package which incorporated several successful behavioral techniques, such as a structured bedtime and reinforcement for compliance to bedtime. While it is not within the scope of the present study to evaluate the separate behavioral mechanisms underlying the Mystery Motivator package the threat of concurrent interventions must be noted.

Generality of participants must be considered as potential qualifiers of the present findings. This study included three boys and one girl between the ages of 5 and 8 years. The Mystery Motivator program may or may not be as effective with older children, adolescents or children with different cultural backgrounds. Generality of parent participants is also a factor that must be considered. Thus, results may only be extended to parents with similar levels of motivation, education, and social support. A related issue is that all materials necessary to carry out the intervention were provided, leaving questions about whether parents could implement the intervention within a less structured model.

Finally, it is notable that two of the three parent participants entered the study with an adequate knowledge of the behavioral concepts 
presented in the Mystery Motivator program. This may suggest that something more than a knowledge of technical skills is necessary for parents to change their own routines and behaviors related to child bedtime. Perhaps the structure of the Mystery Motivator allowed for and encouraged consistent and effective use of pre-existing parenting skills.

Comments Regarding Participant 2. Victoria showed the most variability and least improvement across phases as compared to that of the other three child participants. Concurrent factors in Victoria's setting, including a high degree of family disruption, may account for these findings. Poor outcome to behavioral treatment has previously been associated with more severe behavior problems (Minde et al., 1994). It has also been speculated that severe bedtime opposition may indicate other behavioral problems (Kataria et al., 1987; Walters, 1993). However, Victoria's limited improvements are most likely a result of a chaotic, highly stressful home environment, a factor which repeatedly has been associated with bedtime problems (Quine, 1992; Stores, 1996; Wolfson et al., 1992).

\section{Future Research}

As mentioned, only one previous study has investigated the efficacy of the MM (Moore et al., 1994), and no other study has addressed its use as administered by parents in the home setting. It is clear that future research is needed to validate the use of this intervention for other populations and target behavior problems. For example, this study provided all rewards to families; it is unclear whether the MM would be as effective if parents were to provide the rewards. The efficacy of the MM in treating other populations and different types of behavior problems remains to be seen. Furthermore, a key component of this program is the "mystery" surrounding the delivery of reinforcement, an aspect which could be tested by comparing the MM with other reinforcement schedules (e.g., a fixed rate) to measure its relative intervention power. The separate components of the MM, such as goal-setting, contracting, and public posting, could be assessed for efficacy and individual strength. Finally, a longer follow-up period could be helpful in determining maintenance. 


\section{REFERENCES}

Achenbach, T.M. (1991). Manual for the child behavior checklist/4-18 and 1991 profile. Burlington, VT: University of Vermont Department of Psychiatry.

Adair, R., Zuckerman, B., Bauchner, H., Philipp, B., \& Levinson, S. (1992). Reducing night waking in infancy: A primary care intervention. Pediatrics, 89, 585-588.

Adams, L.A., \& Rickert, V.I. (1989). Reducing bedtime tantrums: Comparison between positive routines and graduated extinction. Pediatrics, 84, 756-761.

Allison, D.B., Burke, J.C., \& Summers, J.A. (1993). Treatment of non specific dyssomnia with simple stimulus control procedures in a child with Down's Syndrome. Canadian Journal of Psychiatry, 38, 274-276.

Ashbaugh, R., \& Peck, S. (1998). Treatment of sleep problems in a toddler: A replication of the faded bedtime with response cost protocol. Journal of Applied Behavior Analysis, 31, 127-129.

Baer, D.M., Wolf, M.M., \& Risley, T.R. (1968). Some current dimensions of applied behavior analysis. Journal of Applied Behavior Analysis, 91-97.

Blader, J.C., Koplewicz, H.S., Abikoff, H., \& Folwy, C. (1997). Sleep problems of elementary school children. Archives of Pediatric and Adolescent Medicine, 151, 473-480.

Blum, D. (1994). When lullabies aren't enough. The New York Times Magazine, October 9, 44.

Carns, A.W., \& Carns, M.R. (1995). Making behavioral contracts successful. School Counselor, 42, 155-160.

Cassidy, A. (1996). Routines that work. Parents, 71 (6), 80.

Chadez, L.H., \& Nurius, P.S. (1987). Stopping bedtime crying: Treating the child and the parents. Journal of Clinical Child Psychology, 16, 212-217.

Cohen, J. (1960). A coefficient of agreement for nominal scales. Educational and Psychological Measurement, 20, 37-46.

Cooper, J.O., Heron, T.E., \& Heward, W.L. (1987). Applied Behavior Analysis. New York: Macmillan Publishing.

Dardig, J.C. \& Heward, W.L. (1981). Sign here: A contracting book for children and their parents ( 2 nd ed). Bridgewater, NJ: Fournies.

Durand, V.M., \& Mindell, J.A. (1990). Behavioral treatment of multiple childhood sleep disorders. Behavior Modification, 14, 37-49.

Edwards, K.J., \& Christophersen, E.R. (1994). Treating common sleep problems of young children. Developmental and Behavioral Pediatrics, 15, 207-213.

Elliott, S.N., \& Von Brock Treuting, M. (1991). The Behavioral Intervention Rating Scale: Development and validation of a pretreatment acceptability and effectiveness measure. Journal of School Psychology, 29, 43-51.

Ferber, R. (1985). Solve your child's sleep problems. New York: Simon and Schuster.

Forehand, R.L., \& Long, N. (1996). Parenting the strong-willed child. Chicago, IL: Contemporary Books.

Forehand, R.L. \& McMahon, R.J. (1981). Helping the noncompliant child: A clinician's guide to parent training. New York: Guilford Press.

Gottman, J.M., \& Leiblum, S.R. (1974). How to do psychotherapy and how to evaluate it. New York: Holt, Rinehart, \& Winston. 
Jenson, W.R., Rhode, G., \& Reavis, H.K. (1994). The tough kid tool box. Longmont, CO: Sopris West.

Jones, D.P., \& Verduyn, C.M. (1983). Behavioral management of sleep problems. Archives of Disease in Childhood, 58, 442-444.

Kitaria, S., Swanson, M.S., \& Trevathan, G.E. (1987). Persistence of sleep disturbances in preschool children. Journal of Pediatrics, 110, 642-646.

Kirschenbaum, D.S., Dielman, J.S., \& Karoloy, P. (1982). Efficacy of behavioral contracting: Target behaviors, performance criteria, and settings. Behavior Modification, $6,499-518$.

Lozoff, B., Wolf, A.W., \& Davis, N.S. (1985). Sleep problems seen in pediatric practice. Pediatrics, 75, 477-483.

Malott, R.W., Whaley, D.L., \& Malott, M.E. (1991). Elementary principles of behavior, 2nd Ed. Englewood Cliffs, NJ: Prentice Hall.

Milan, M.A., Mitchell, Z.P., Berger, M.I., \& Pierson, D.F. (1982). Positive routines: A rapid alternative to extinction for elimination of bedtime tantrum behavior. Child Behavior Therapy, 3, 13-25.

Minde, K., Faucon, A., \& Falkner, S. (1994). Sleep problems in toddlers: Effects of treatment on their daytime behavior. Journal of the American Academy of Child and Adolescent Psychiatry, 33, 1114-1121.

Moore, L.A., Waguespack, A.M., Wickstrom, K.F., Witt, J.C., \& Gaydos, G.R. (1994). Mystery motivator: An effective and time efficient intervention. School Psychology Review, 23, 106-118.

Piazza, C.C., \& Fisher, W. (1991). A faded bedtime with response cost protocol for treatment of multiple sleep problems in children. Journal of Applied Behavior Analysis, 24, 129-140.

Quine, L. (1992). Severity of sleep problems in children with severe learning difficulties: Description and correlates. Journal of Community and Applied Social Psychology, 247-268.

Rhode, G.R., Jenson, W.R., \& Reavis, H.K. (1992). The tough kid book: Practical classroom management strategies. Longmont, CO: Sopris West.

Richman, N., Douglas, J., Hunt, H., Lansdown, R., \& Levere, R. (1985). Behavioral methods in the treatment of sleep disorders-a pilot study. Journal of Child Psychology and Psychiatry, 26, 581-590.

Richman, N. (1981). A community survey of the characteristics of one to two year olds with sleep disruptions. Journal of the American Academy of Child Psychiatry, 20, 281-291.

Rolider, A., \& Van Houten, R. (1984a). Training parents to use extinction to eliminate nighttime crying by gradually increasing the criteria for ignoring crying. Education and Treatment of Children, 7, 119-124.

Rolider, A., \& Van Houten, R. (1984b). The effects of dro alone and dro plus reprimands on the undesirable behavior of three children in home settings. Education and Treatment of Children, 7, 17-31.

Scott, G., \& Richards, M.P.M. (1990). Night waking in one-year-old children in England. Child Care Health and Development, 16, 283-302.

Seymour, F.W., Brock, P., During, M., \& Poole, G. (1989). Reducing sleep disruptions in young children: Evaluation of therapist-guided and written information 
approaches: A brief report. Journal of Child Psychology and Psychiatry and Allied Disciplines, 30, 913-918.

Siegel, P. (1995). Helping your child-and you-get a good night's sleep. Good Housekeeping, 221, 157.

Sloane, H.N. (1979). The good kid book. Champaign, IL: Research Press.

Stores, G. (1996). Practitioner review: Assessment and treatment of sleep disorders in children and adolescents. Journal of Child Psychology and Psychiatry, 37, 907-925.

Szykula, S.A. (1991). Parenting cookbook. Eugene, OR: Family First Productions.

Walters, J. (1993). Sleep management: The hidden agenda. Child: Care, Health and Development, 19, 197-208.

Williams, C.D. (1959). The elimination of tantrum behaviors by extinction procedures. Journal of Abnormal and Social Psychology, 59, 269-270.

Witt, J.C., \& Elliott, S.N. (1985). Acceptability of classroom intervention strategies. In T. R. Kratochwill (Ed.), Advances in school psychology (Vol. 4, pp. 251-288). Hillsdale, NJ: Lawrence Erlbaum Associates.

Wolfson, A., Lacks, P., \& Futterman, A. (1992). Effects of parent training on infant sleeping patterns, parents' stress, and perceived parental competence. Journal of Consulting and Clinical Psychology, 60, 41-48.

RECEIVED: 02/15/99

REVISED: 04/30/99

ACCEPTED: 05/10/99 